Jurnal Ilmu Ilmu Agribisnis: Journal of Agribusiness Science, 9(2), Mei 2021

\title{
STRUKTUR BIAYA, KEUNTUNGAN, DAN NILAI TAMBAH AGROINDUSTRI GULA KELAPA DI KECAMATAN NEGERI KATON KABUPATEN PESAWARAN
}

\author{
(Cost Structure, Profit, and Added Value Analysis of Coconut Sugar Agroindustry \\ in Negeri Katon Subdistrict, Pesawaran Regency)
}

Ayla Vilin Windyata, Dwi Haryono, Maya Riantini

Jurusan Agribisnis, Fakultas Pertanian, Universitas Lampung, Jl. Prof. Dr. Soemantri Brojonegoro No. 1 Bandar Lampung 35145, e-mail: dwi.haryono@fp.unila.ac.id

\begin{abstract}
This research aims to analyze the structure of costs, profit, and added value of coconut agroindustry. This research was a survey method of 38 coconut sugar agroindustries in Negeri Katon Subdistrict, Pesawaran Regency. The data of this research were collected in December 2019 - January 2020. The analytical methods used in this research were cost structure analysis of total costs, profit analysis based on revenue and total costs, and Hayami added value analysis. The results of this research indicated that the biggest cost component of the cost structure of coconut sugar production were palm juice (44.21\%), then followed by labor cost $(24.22 \%)$, firewood cost $(15.43 \%)$, transportation cost $(8.45 \%)$, wooden box cost (3.47\%), tool depreciation cost (1.67\%), sodium cost (1.55\%), plastic cost (0.69\%), and whiting cost (0.31\%). Coconut sugar agroindustry in Negeri Katon Subdistrict Pesawaran Regency received profit as much as IDR1,549,174.33/month. Added value of coconut sugar was IDR1,111.22/liter of raw material. It indicated that coconut sugar agroindustry in Negeri Katon Subdistrict Pesawaran Regency had a positive added value and feasible to be developed.
\end{abstract}

Key words: agroindustry, coconut sugar, cost structure, profit, added value

\section{PENDAHULUAN}

Industri pengolahan adalah suatu kegiatan ekonomi yang melakukan kegiatan mengubah suatu barang dasar secara mekanis, kimia, ataupun manual sehingga menjadi barang yang lebih tinggi nilainya. Industri pengolahan erat kaitannya dengan sektor pertanian sebagai sektor utama penghasil pangan. Kegiatan utama industri pengolahan produk pertanian adalah mengolah hasil pertanian menjadi makanan dan minuman yang memiliki nilai tambah (Widodo 2003).

Kabupaten Pesawaran merupakan salah satu kabupaten di Provinsi Lampung yang pertumbuhan ekonominya sebagian besar didukung oleh sektor industri pengolahan. Berdasarkan data Badan Pusat Statistik (BPS) Kabupaten Pesawaran (2019), sektor industri pengolahan memberikan sumbangan terhadap Produk Domestik Regional Bruto (PDRB) sebesar 14,49 persen dari total keseluruhan PDRB. Sektor industri pengolahan menempati posisi kedua terbesar dalam memberikan kontribusi terhadap perekonomian Kabupaten Pesawaran. Besarnya peran sektor pertanian di Kabupaten Pesawaran diiringi dengan semakin besarnya peran sektor industri pengolahan.
Agroindustri yang ada di Kabupaten Pesawaran terbilang cukup banyak, yaitu 874 agroindustri. Jumlah terbanyak berada di Kecamatan Gedong Tataan yaitu 264 agroindustri dan posisi terbanyak kedua ditempati oleh Kecamatan Negeri Katon yaitu berjumlah 206 agroindustri (BPS Kabupaten Pesawaran 2019). Salah satu komoditas pertanian yang potensial untuk dikembangkan oleh pelaku agroindustri di Kecamatan Negeri Katon adalah kelapa. Masyarakat di Kecamatan Negeri Katon memanfaatkan tanaman kelapa untuk diolah menjadi gula kelapa.

Jumlah pengrajin gula kelapa di Kecamatan Negeri Katon sebanyak 114 orang yang tersebar di beberapa desa, yaitu Desa Lumbirejo, Desa Tri Rahayu, Desa Pujo Rahayu, Desa Purworejo, Desa Karang Rejo, dan Desa Kalirejo (Profil Kecamatan Negeri Katon 2019). Jumlah pengrajin gula kelapa di Kecamatan Negeri Katon sangat banyak sehingga Kecamatan Negeri Katon dapat dikatakan sebagai sentra agroindustri gula kelapa di Kabupaten Pesawaran saat ini.

Jika nira kelapa dijual tanpa melalui proses pengolahan, maka harga yang diterima sangat rendah, yaitu Rp1.000,00 - Rp1.500,00 per liter. 
Pengrajin mengeluarkan biaya bahan baku, biaya bahan bakar, kapur sirih, dan lain-lain untuk memproduksi gula kelapa yang harga jualnya Rp11.000,00/kg. Penelitian ini bertujuan untuk menganalisis struktur biaya yang dikeluarkan oleh agroindustri, keuntungan yang diperoleh agroindustri, dan nilai tambah gula kelapa.

\section{METODE PENELITIAN}

\section{Lokasi, Responden, dan Data}

Metode penelitian yang digunakan adalah metode survei. Lokasi penelitian dipilih secara sengaja (purposive) dengan pertimbangan bahwa Kecamatan Negeri Katon merupakan salah satu kecamatan yang memiliki jumlah agroindustri gula kelapa yang cukup banyak, yaitu 114 agroindustri (Kantor Kecamatan Negeri Katon 2019). Waktu pengumpulan data dilakukan pada bulan Desember 2019 - Januari 2020. Metode pengambilan sampel menggunakan simple random sampling.

Penentuan jumlah sampel dilakukan dengan menggunakan rumus Slovin yang terdapat dalam Umar (2002), yaitu sebagai berikut :

$\mathrm{n}=\frac{N}{\mathrm{~N}\left(\mathrm{~d}^{2}\right)+1}$

Keterangan :

$\mathrm{n}=$ jumlah sampel

$\mathrm{N}=$ jumlah populasi (114)

$\mathrm{d}=$ tingkat presisi 13 persen $(0,13)$

Berdasarkan hasil perhitungan dengan menggunakan rumus di atas, maka diperoleh jumlah responden yang akan dijadikan sebagai sampel penelitian yaitu sebanyak 38 agroindustri.

Jenis data yang digunakan dalam penelitian ini adalah data primer dan data sekunder. Data primer diperoleh melalui wawancara secara langsung dengan responden menggunakan kuisioner penelitian. Data sekunder diperoleh studi dokumentasi, yaitu dengan mempelajari dan mengamati dokumen, catatan tertulis, dan arsiparsip lainnya dari instansi pemerintahan yang terkait dengan penelitian.

Metode analisis data yang digunakan pada penelitian ini adalah metode analisis deskriptif kualitatif dan analisis deskriptif kuantitatif. Analisis deskriptif kualitatif digunakan untuk menganalisis struktur biaya, sedangkan analisis deskriptif kuantitatif digunakan untuk menganalisis keuntungan dan nilai tambah.

\section{Analisis Struktur Biaya}

Persentase dari setiap struktur biaya dapat diketahui dengan menggunakan rumus menurut Sumodiningrat dan Iswara (1993), yaitu :

$P=\frac{\text { NTFC atau NTVC }}{\text { NTC }} \times 100 \%$

Keterangan :

$\mathrm{P} \quad=$ Nilai dari struktur biaya produksi $(\%)$

NTFC = Nilai dari komponen biaya tetap (Rp)

NTVC $=$ Nilai dari komponen biaya variabel $(\mathrm{Rp})$

NTC = Nilai dari total biaya produksi $(\mathrm{Rp})$

\section{Analisis Keuntungan}

Keuntungan dari suatu agroindustri dapat diperoleh dengan cara menghitung selisih antara pendapatan yang diterima dari hasil usaha dengan total biaya produksi yang dikeluarkan (Soekartawi 2000). Secara matematis, menghitung keuntungan dapat dilakukan dengan rumus :

$\pi=\mathrm{TR}-\mathrm{TC}$

$\pi=(\mathrm{Y} . \mathrm{Py})-(\mathrm{X} . \mathrm{Px})$

Keterangan:

$\pi \quad=$ Keuntungan $(\mathrm{Rp})$

$\mathrm{TR}=$ Total pendapatan $(\mathrm{Rp})$

$\mathrm{TC}=$ Total biaya $(\mathrm{Rp})$

$\mathrm{Y}=$ Jumlah produksi $(\mathrm{kg})$

Py $=$ Harga satuan produksi $(\mathrm{Rp})$

$\mathrm{X}=$ Faktor produksi $(\mathrm{i}=1,2,3, \ldots, \mathrm{n})$

$\mathrm{Px}=$ Harga faktor produksi ke-i (Rp)

\section{Analisis Nilai Tambah}

Nilai tambah dihitung untuk mengetahui seberapa besar selisih harga antara nira kelapa dengan olahan gula kelapa. Selisih harga tersebut yang akan menambah pendapatan pelaku agroindustri gula kelapa di Kecamatan Negeri Katon Kabupaten Pasawaran. Nilai tambah dari nira kelapa menjadi gula kelapa dapat diketahui dengan menggunakan metode nilai tambah Hayami. Perhitungan nilai tambah menggunakan metode Hayami seperti yang dilakukan oleh Sari, Zakaria, dan Affandi (2015). Prosedur perhitungan nilai tambah dengan metode Hayami dapat dilihat pada Tabel 1. 
Tabel 1. Prosedur perhitungan nilai tambah

\begin{tabular}{|c|c|c|}
\hline \multirow{2}{*}{ No. } & Variabel & \multirow{2}{*}{ Formula } \\
\hline & Output, Input, Harga & \\
\hline 1 & Hasil produksi (kg) & $\mathrm{A}$ \\
\hline 2 & Bahan baku (liter) & $\mathrm{B}$ \\
\hline 3 & Tenaga kerja (HOK) & $\mathrm{C}$ \\
\hline 4 & Faktor konversi & $\mathrm{D}=\mathrm{A} / \mathrm{B}$ \\
\hline 5 & Koefisien tenaga kerja & $\mathrm{E}=\mathrm{C} / \mathrm{B}$ \\
\hline 6 & Harga produk & $\mathrm{F}$ \\
\hline 7 & $\begin{array}{l}\text { Upah rata-rata tenaga kerja } \\
\text { (Rp/HOK) }\end{array}$ & $\mathrm{G}$ \\
\hline \multicolumn{3}{|c|}{ Pendapatan dan Keuntungan } \\
\hline 8 & $\begin{array}{l}\text { Harga bahan baku } \\
\text { (Rp/liter) }\end{array}$ & $\mathrm{H}$ \\
\hline 9 & $\begin{array}{l}\text { Sumbangan input lain } \\
\text { (Rp/liter) }\end{array}$ & I \\
\hline 10 & Nilai Output & $\mathrm{J}=\mathrm{D} \times \mathrm{F}$ \\
\hline 11 & $\begin{array}{l}\text { a. Nilai tambah } \\
\text { b. Rasio nilai tambah }\end{array}$ & $\begin{array}{l}\mathrm{K}=\mathrm{J}-\mathrm{I}-\mathrm{H} \\
\mathrm{L} \%=(\mathrm{K} / \mathrm{J}) \times 100 \%\end{array}$ \\
\hline 12 & $\begin{array}{l}\text { a. Imbalan tenaga kerja } \\
\text { b. Bagian tenaga kerja }\end{array}$ & $\begin{array}{l}\mathrm{M}=\mathrm{E} \times \mathrm{G} \\
\mathrm{N} \%=(\mathrm{M} / \mathrm{K}) \times 100 \%\end{array}$ \\
\hline 13 & $\begin{array}{l}\text { a. Keuntungan } \\
\text { b. Tingkat keuntungan }\end{array}$ & $\begin{array}{l}\mathrm{O}=\mathrm{K}-\mathrm{M} \\
\mathrm{P} \%=(\mathrm{O} / \mathrm{K}) \times 100 \%\end{array}$ \\
\hline \multicolumn{3}{|c|}{ Balas Jasa untuk Faktor Produksi } \\
\hline 14 & $\begin{array}{l}\text { Margin keuntungan } \\
\text { a. Keuntungan } \\
\text { b. Tenaga kerja } \\
\text { c. Faktor produksi lain }\end{array}$ & $\begin{array}{l}\mathrm{Q}=\mathrm{J}-\mathrm{H} \\
\mathrm{R}=\mathrm{O} / \mathrm{Q} \times 100 \% \\
\mathrm{~S}=\mathrm{M} / \mathrm{Q} \times 100 \% \\
\mathrm{~T}=\mathrm{I} / \mathrm{Q} \times 100 \%\end{array}$ \\
\hline
\end{tabular}

Sumber: Hayami, et al., 1987 dalam Sari, Zakaria, dan Affandi, 2015

Kriteria nilai tambah adalah :

1. Jika NT >0, berarti pengembangan agroindustri gula kelapa memberikan nilai tambah atau hasilnya positif.

2. Jika NT < 0, berarti pengembangan agroindustri gula kelapa tidak memberikan nilai tambah atau hasilnya negatif.

\section{HASIL DAN PEMBAHASAN}

\section{Karakteristik Responden}

Umur responden berkisar antara 27 - 53 tahun. Mantra (2004) menjelaskan bahwa usia produktif penduduk berada pada kisaran 15 - 64 tahun, maka seluruh responden penelitian berada pada usia produktif. Kelompok umur $36-44$ tahun merupakan kelompok umur terbanyak dengan persentase 50 persen. Berdasarkan tingkat pendidikan responden, tingkat pendidikan tamat Sekolah Menengah Pertama (SMP) merupakan kategori dengan jumlah responden terbanyak, yaitu sebesar 39 persen. Pengalaman usaha kisaran antara 7 - 11 tahun jumlahnya paling banyak, yaitu sebesar 47 persen. Responden pengrajin gula kelapa sebagian besar tidak memiliki pekerjaan sampingan dengan persentase 47 persen. Responden pengrajin gula kelapa memiliki jumlah tanggungan keluarga berkisar antara $1-6$ orang. Jumlah tanggungan keluarga responden terbanyak berada pada kisaran $3-4$ orang, yaitu sebesar 66 persen.

\section{Struktur Biaya dan Keuntungan}

Biaya produksi pada agroindustri gula kelapa di Kecamatan Negeri Katon terdiri dari biaya bahan baku, biaya tenaga kerja, dan biaya overhead pabrik. Biaya bahan baku merupakan biaya yang dikeluarkan oleh pengrajin untuk memperoleh nira kelapa sebagai bahan baku pembuatan gula kelapa. Walaupun para pengrajin memperoleh nira dari kebun kelapa milik sendiri, akan tetapi biaya bahan baku tetap diperhitungkan ke dalam biaya produksi. Biaya overhead pabrik merupakan biaya yang akan berubah sejalan dengan perubahan volume produksi. Perhitungan keuntungan dan struktur biaya pada agroindustri gula kelapa di Kecamatan Negeri Katon Kabupaten Pesawaran dapat dilihat pada Tabel 2.

Tabel 2 menunjukkan bahwa rata-rata pendapatan yang diterima oleh responden pengrajin gula kelapa per bulan adalah sebesar Rp4.390.736,84, sedangkan biaya total yang dikeluarkan sebesar Rp2.841.562,51. Pendapatan agroindustri gula kelapa dipengaruhi oleh biaya produksi dan jumlah produksi. Rata-rata jumlah produksi gula kelapa sebesar 399,16 kg per bulan. Semakin besarnya jumlah produksi yang dihasilkan oleh agroindustri gula kelapa, maka semakin besar pula pendapatan yang diperoleh. Namun demikian, meningkatnya jumlah produksi selalu didukung oleh jumlah faktor produksi (input) yang digunakan. Biaya produksi terbesar berasal dari biaya bahan baku karena jumlah penggunaan nira kelapa paling banyak dibandingkan penggunaan faktor produksi lainnya, yaitu sebanyak 1.995,79 liter dalam satu bulan.

Kondisi ini sejalan dengan penelitian Salsabila, Haryono, dan Syarief (2019) bahwa biaya produksi terbesar yang dikeluarkan oleh agroindustri adalah biaya bahan baku, yaitu sebesar Rp4.468.333,33 dari total biaya sebesar Rp7.620.797,57 karena jumlah bahan baku yang diolah dalam satu bulan sebanyak 684,17 kg. Jumlah penggunaan bahan baku ini paling besar diantara penggunaan faktor 
Jurnal Ilmu Ilmu Agribisnis: Journal of Agribusiness Science, 9(2), Mei 2021

Tabel 2. Struktur biaya dan keuntungan pada agroindustri gula kelapa di Kecamatan Negeri Katon Kabupaten Pesawaran per bulan

\begin{tabular}{|c|c|c|c|c|c|c|}
\hline \multirow{2}{*}{ No. } & \multirow{2}{*}{ Uraian } & \multicolumn{4}{|c|}{ Per Bulan } & \multirow{2}{*}{$\frac{\text { Struktur Biaya }}{(\%)}$} \\
\hline & & Satuan & Jumlah & Harga $(\mathrm{Rp})$ & Nilai (Rp) & \\
\hline \multirow[t]{2}{*}{1} & Pendapatan & & & & & \\
\hline & Produksi & $\mathrm{Kg}$ & 399,16 & $11.000,00$ & $4.390 .736,84$ & \\
\hline \multirow[t]{12}{*}{2} & $\begin{array}{l}\text { Biaya Produksi } \\
\text { 1. Biaya Bahan Baku }\end{array}$ & & & & & \\
\hline & Nira Kelapa & Liter & $1.995,79$ & 629,52 & $1.256 .388,86$ & 44,21 \\
\hline & $\begin{array}{l}\text { 2. Biaya Tenaga Kerja } \\
\text { 3. Biaya Overhead Pabrik } \\
\text { Biaya Bahan Tidak } \\
\text { Langsung }\end{array}$ & $\mathrm{HOK}$ & 27,53 & $25.000,00$ & $688.322,37$ & 24,22 \\
\hline & Kayu Bakar & Kubik & 6,26 & $70.000,00$ & $438.421,05$ & 15,43 \\
\hline & Kapur Sirih & $\mathrm{Kg}$ & 2,20 & $4.000,00$ & $8.789,47$ & 0,31 \\
\hline & Sodium & $\mathrm{Kg}$ & 2,20 & $20.000,00$ & $43.947,37$ & 1,55 \\
\hline & Kotak Kayu & Pcs & 39,42 & $2.500,00$ & $98.552,63$ & 3,47 \\
\hline & $\begin{array}{l}\text { Plastik } \\
\text { Biaya Tidak Langsung }\end{array}$ & Pcs & 39,42 & 500,00 & $19.710,53$ & 0,69 \\
\hline & Biaya Transportasi & $\mathrm{Rp}$ & 24,00 & $10.000,00$ & $240.000,00$ & 8,45 \\
\hline & Penyusutan & $\mathrm{Rp}$ & 24,00 & $10.000,00$ & $47.430,23$ & 1,67 \\
\hline & Total Biaya Overhead Pabrik & $\mathrm{Rp}$ & & & $896.851,28$ & 31,56 \\
\hline & Total Biaya & $\mathrm{Rp}$ & & & $2.841 .562,51$ & 100,00 \\
\hline 3 & Keuntungan & $\mathrm{Rp}$ & & & $1.549 .174,33$ & \\
\hline
\end{tabular}

Berdasarkan perhitungan, keuntungan yang diperoleh agroindustri sebesar Rp1.549.174,33 per bulan, maka dapat dikatakan bahwa agroindustri gula kelapa di Kecamatan Negeri Katon menguntungkan dan layak untuk dikembangkan. Hasil penelitian ini sejalan dengan hasil penelitian Pardani (2015) bahwa agroindustri gula semut menguntungkan dan layak untuk dikembangkan karena keuntungan yang diperoleh sebesar Rp290.108,11 per satu kali produksi.

Komponen biaya yang paling banyak dikeluarkan adalah biaya nira kelapa dengan persentase sebesar 44,21 persen, biaya tenaga kerja dengan persentase sebesar 24,22 persen, dan biaya kayu bakar dengan persentase sebesar 15,43 persen. Persentase dari ketiga komponen biaya tersebut menunjukkan bahwa biaya nira kelapa, biaya tenaga kerja, dan biaya kayu bakar kurang efisien atau belum ideal dalam agroindustri gula kelapa. Ketiga komponen biaya tersebut dapat ditekan atau diminimalisir agar dapat meningkatkan keuntungan, yaitu dengan cara memaksimalkan produktivitas pohon kelapa milik pengrajin agar dapat menghasilkan nira lebih banyak, menggunakan kayu bakar dari kebun sendiri atau menekan penggunaan kayu bakar, dan mengurangi penggunaan tenaga kerja langsung. Hasil penelitian ini sejalan dengan hasil penelitian Anggraeni (2017) yang menunjukkan bahwa struktur biaya yang dikeluarkan oleh agroindustri didominasi oleh biaya bahan baku dan biaya tenaga kerja.
Komponen biaya transportasi memiliki kontribusi terhadap biaya total sebesar 8,45 persen. Persentase tersebut menunjukkan bahwa biaya transportasi kurang efisien atau belum ideal dalam agroindustri gula kelapa. Komponen biaya transportasi dapat diminimalisir dengan mengurangi penggunaan bensin. Berhubung jarak antara lokasi agroindustri dengan pengepul dekat, pengrajin dapat berjalan kaki mengantarkan hasil produksi mereka atau meminta pengepul mengambil hasil produksi ke lokasi agroindustri.

Komponen biaya lainnya adalah, biaya kotak kayu, biaya penyusutan peralatan, biaya sodium, biaya plastik, dan biaya kapur sirih. Masing-masing komponen biaya tersebut secara berurutan memiliki persentase sebesar 3,47 persen, 1,67 persen, 1,55 persen, 0,69 persen, dan 0,31 persen. Persentase tersebut menunjukkan bahwa penggunaan sodium, kotak kayu, penyusutan peralatan, plastik, dan kapur sirih cukup efisien atau sudah ideal karena persentase tidak terlalu besar terhadap biaya total yang dikeluarkan.

\section{Nilai Tambah Gula Kelapa}

Analisis nilai tambah dilakukan untuk mengetahui besarnya nilai tambah yang diperoleh dari pengolahan nira kelapa menjadi gula kelapa. Nilai tambah didapat dari selisih antara nilai output dari nira kelapa yang telah mendapat perlakuan tertentu dengan biaya-biaya yang dikeluarkan selama 
proses produksi. Analisis nilai tambah pada penelitian ini dilakukan dalam kurun waktu satu bulan yaitu pada bulan November - Desember 2019. Nilai tambah pada agroindustri gula kelapa dapat dilihat pada Tabel 3 .

Berdasarkan hasil analisis pada Tabel 3, nilai faktor konversi yang diperoleh adalah sebesar 0,20, artinya setiap satu liter nira kelapa yang diolah oleh agroindustri akan menghasilkan rata-rata gula kelapa sebanyak $0,20 \mathrm{~kg}$. Dalam pembuatan satu kilogram gula kelapa, rata-rata sumbangan input lain yang digunakan adalah sebesar Rp459,26, nilai ini diperoleh dari pembagian biaya total rata-rata dari bahan tidak langsung, biaya transportasi, dan biaya penyusutan alat dengan jumlah rata-rata bahan baku (nira kelapa) yang digunakan.

Sumbangan input lain terbesar pada pengolahan gula kelapa adalah dari penggunaan kayu bakar dan biaya transportasi. Adapun imbalan tenaga kerja merupakan suatu balas jasa atas keterlibatan tenaga kerja dalam produksi, diperoleh dari perkalian jumlah tenaga kerja per unit bahan baku terhadap tingkat upah yang berlaku. Nilai imbalan tenaga kerja yang diperoleh yaitu sebesar Rp344,89, artinya bahwa setiap satu liter bahan baku (nira kelapa) yang diolah oleh agroindustri gula kelapa, maka akan menghasilkan imbalan bagi tenaga kerja sebesar Rp344,89 per liter.

Tabel 3. Nilai tambah pada agroindustri gula kelapa di Kecamatan Negeri Katon Kabupaten Pesawaran

\begin{tabular}{clr}
\hline \multirow{2}{*}{ No. } & \multicolumn{1}{c}{ Variabel } & \multicolumn{1}{c}{ Per Bulan } \\
\cline { 3 - 3 } & & \multicolumn{1}{c}{ Nilai } \\
\hline Output, Input, dan Harga & 399,16 \\
1 & Output (kg/bulan) & 1995,79 \\
2 & Bahan baku (liter/bulan) & 27,53 \\
3 & Tenaga kerja (HOK/bulan) & 0,20 \\
4 & Faktor konversi & 0,01 \\
5 & Koefisien tenaga kerja (HOK) & $11.000,00$ \\
6 & Harga output & $25.000,00$ \\
7 & Upah rata-rata tenaga kerja (Rp/HOK) \\
\hline Pendapatan dan Keuntungan & 629,52 \\
8 & Harga bahan baku (Rp/liter) & 459,26 \\
9 & Sumbangan input lain (Rp/liter) & $2.200,00$ \\
10 & Nilai output (Rp/kg) & $1.111,22$ \\
11 & a. Nilai tambah (Rp/liter) & 50,51 \\
& b. Rasio nilai tambah (\%) & 344,89 \\
12 & a. Imbalan tenaga kerja (Rp/liter) & 31,04 \\
& b. Bagian tenaga kerja (\%) & 766,33 \\
13 & a. Keuntungan (Rp/kg) & 68,96 \\
\hline & b. Tingkat keuntungan & $1.570,48$ \\
\hline Balas Jasa Pemilik Faktor-Faktor Produksi & 48,80 \\
14 & Marjin Keuntungan (Rp/kg) & 21,96 \\
& a. Keuntungan (\%) & 29,24 \\
\hline & b. Tenaga kerja (\%) &
\end{tabular}

Nilai marjin keuntungan pada agroindustri gula kelapa lebih besar dibandingkan dengan nilai tambah, artinya bahwa pada penelitian ini, perhitungan nilai tambah lebih tepat digunakan untuk melihat seberapa besar keuntungan yang diperoleh agroindustri gula kelapa. Hasil penelitian ini sejalan dengan hasil penelitian Sari, Hasyim, dan Widjaja (2018), yang menunjukkan bahwa nilai marjin keuntungan lebih besar dibandingkan dengan nilai tambah yang diperoleh agroindustri.

Agroindustri gula kelapa di Kecamatan Negeri Katon termasuk dalam agroindustri padat modal karena nilai balas jasa pemilik terhadap nilai keuntungan lebih besar dibandingkan terhadap tenaga kerja, yang artinya agroindustri gula kelapa lebih mengutamakan modal dibandingkan tenaga kerja. Tenaga kerja pada agroindustri gula kelapa sebagian besar berasal dari dalam keluarga dan kegiatan produksi masih mampu ditangani sendiri. Modal digunakan oleh pengrajin gula kelapa untuk memperlancar kegiatan operasional. Hasil penelitian ini sejalan dengan penelitian Utama, Widjaja, dan Kasymir (2016), yang menyimpulkan bahwa agroindustri cocofiber merupakan agroindustri pada modal karena nilai balas jasa pemilik terhadap nilai keuntungan lebih besar dibandingkan terhadap tenaga kerja.

\section{KESIMPULAN}

Hasil penelitian ini menunjukkan bahwa biaya bahan baku merupakan komponen biaya paling besar. Kemudian diikuti oleh biaya tenaga kerja, biaya kayu bakar, dan biaya transportasi. Agroindustri gula kelapa di Kecamatan Negeri Katon Kabupaten Pesawaran merupakan unit usaha yang menguntungkan dengan jumah keuntungan sebesar Rp1.549.174,33. Nilai tambah gula kelapa $50,51 \%$ dari nilai produk, yaitu sebesar Rp1.111,22, yang artinya agroindustri gula kelapa layak untuk dikembangkan.

\section{DAFTAR PUSTAKA}

Anggraeni TS, Lestari DAH, dan Indriani Y. 2017. Keragaan agroindustri tempe anggota Primkopti Kabupaten Pesawaran. Jurnal Ilmu Ilmu Agribisnis, 5(3): 275-282. https://jurnal.fp.unila.ac.id/index.php/JIA/artic le/view/1640. [24 Juni 2020].

BPS [Badan Pusat Statistik] Kabupaten Pesawaran. 2019a. Produk Domestik Regional Bruto (PDRB) Kabupaten Pesawaran Menurut Lapangan Usaha 2017-2018. BPS Kabupaten Pesawaran. Pesawaran. 
$2019 b$.

Persebaran Industri Makanan Kerajinan Rakyat. BPS Kabupaten Pesawaran. Pesawaran.

Kantor Kecamatan Negeri Katon. 2019. Profil Kecamatan Negeri Katon. Kecamatan Negeri Katon. Pesawaran.

Lubis WW, Sihombing L, dan Salmiah. 2013. Analisis nilai tambah usaha pengolahan gula aren di Desa Suka Maju Kecamatan Sibolangit Kabupaten Deli Serdang. Journal on Social Economic of Agriculture and Agribusiness, 2(4): 1-13. http://jurnal.usu.ac.id/index.php/ceress/article/ view/7856. [12 Oktober 2019].

Mantra IB. 2004. Demografi Umum. Penerbit Pustaka Pelajar. Yogyakarta.

Pardani C. 2015. Peningkatan pendapatan pengrajin gula melalui agroindustri gula semut di Kabupaten Tasikmalaya. Mimbar Agribisnis, 1(1): 23-30. http://jurnal.unigal.ac.id/index.php/mimbaragr ibisnis/article/view/28. [10 Oktober 2019].

Salsabila S, Haryono D, dan Syarief YA. 2019. Analisis pendapatan dan nilai tambah agroindustri keripik pisang di Desa Sungai Langka Kecamatan Gedong Tataan Kabupaten Pesawaran. Jurnal Ilmu Ilmu Agribisnis, 7(1) : 68-74. https://jurnal.fp.unila.ac.id/index.php/JIA/artic le/view/3333. [20 Mei 2020].

Sari IRM., Zakaria WA, dan Affandi MI. 2015. Kinerja produksi dan nilai tambah agroindustri emping melinjo di Kota Bandar Lampung. Jurnal Ilmu Ilmu Agribisnis, 3(1) :
18-25.

https://jurnal.fp.unila.ac.id/index.php/JIA/artic le/view/1013. [15 Oktober 2019].

Sari RY, Hasyim AI, dan Widjaya S. 2018. Rantai pasok dan nilai tambah keripik nangka pada agroindustri keripik Panda Alami di Kecamatan Gedong Tataan Kabupaten Pesawaran. Jurnal Ilmu Ilmu Agribisnis, 6(3): 257-262.

https://jurnal.fp.unila.ac.id/index.php/JIA/artic le/view/3022. [16 Oktober 2019].

Soekartawi. 2000. Pengantar Agroindustri. PT Raja Grafindo Persada. Jakarta.

Sugiyono. 2010. Metode Penelitian Kuantitatif, Kualitatif dan $R \& D$. Alfabeta. Bandung.

Sukirno S. 2006. Mikro Ekonomi Teori Pengantar. Edisi Ketiga. PT Raja Grafindo Persada. Jakarta.

Sumodiningrat G dan Iswara AL. 1993. Ekonomi Produksi. Karunika. Universitas Terbuka. Jakarta.

Umar H. 2002. Riset Pemasaran dan Perilaku Konsumen. Gramedia Pustaka Utama. Jakarta.

Utama CP, Widjaya S, dan Kasymir E. 2016. Analisis kelayakan finansial dan nilai tambah agroindustri serat sabut kelapa (cocofiber) di Kecamatan Ketibung Kabupaten Lampung Selatan. Jurnal Ilmu Ilmu Agribisnis, 4(4) : 359-366.

https://jurnal.fp.unila.ac.id/index.php/JIA/artic le/view/1517. [20 Oktober 2019].

Widodo S. 2003. Peran Agribisnis Usaha Kecil dan Menengah untuk Memperkokoh Ekonomi Nasional. Liberty. Yogyakarta. 